Hanzu-Pazara Loredana ${ }^{1}$, Martinescu Alina ${ }^{2}$, Suta Maria ${ }^{3}$

\title{
HLA-DRB1 Frequency in Romanian patients with early rheumatoid arthritis
}

\author{
"'Ovidius" University of Constanta, Faculty of Medicine, Ist Department - Preclinical disciplines - Discipline \\ of Pathology and Immunology, Romania \\ 2 "Ovidius" University of Constanta, Faculty of Medicine, Ist Department - Preclinical disciplines - Discipline \\ of Genetics, Romania \\ 3"Ovidius" University of Constanta, Faculty of Medicine, Ind Department - Medical clinical disciplines - \\ Discipline of Rheumatology, Romania
}

\begin{abstract}
.
As being the most debated polygenic disease, rheumatoid arthritis elicits great interest in the study of association with genetic factors in various ethnic and racial groups. Some of the HLA-DRB1 alleles are encoding shared epitope amino acids that are not conferring the same risk in various populations. Our study focuses on the evaluation of the distribution of HLA-DRB1 alleles in Romanian patients with early rheumatoid arthritis, along with controls by using PCRSSP method. HLA-DRB1 allele genotyping showed statistically significant differences given by a higher allele frequency for $* 04, * 01$ and $* 14$. Also, in our study was observed a lower frequency for $* 03,{ }^{*} 11,{ }^{*} 13$ and $* 15$ HLA-DRB1 allele in patients group compared with controls, also a high frequency for *0404 and *0408 allele, in contrast with *0401 and *0402 which were significantly lower in patients than in controls. *0403, *0405 and *10 were not associated with early rheumatoid arthritis in our group diagnosed according with new classification criteria ACR/EULAR 2010. In present study we found a negative association of *0402, *11 and *13 with early rheumatoid arthritis. Results of our study are demonstrating the need of a continuous work of allele tracing and associating with rheumatoid arthritis, especially in cases early diagnosed in order to create sufficient premises for instituting a correct and possibly long term remissive treatment.
\end{abstract}

Keywords: early rheumatoid arthritis; HLA-DRB1; allele distribution

Loredana Hanzu-Pazara

Faculty of Medicine, Constanta

University Street, No. 1, Campus B, Constanta, Romania

Email: loredanapazara@yahoo.com

\section{Introduction}

As being the most frequent chronic disease of the world, rheumatoid arthritis has a plurifactorial pathogenesis dominated by genetic factors that seem to contribute in 40 to $60 \%$ of the total risk [1]. A lot of genetic factors have been investigated and from all, the HLA-DRB1 gene appears clearly connected to disease, association that was first suggested over 30 years ago and elaborated later by Gregersen and his colleagues [2]. Several HAL-DRB1 alleles (DRB1*0101, DRB1*0102, DRB1*0401, DRB1*0404, DRB1*0405, DRB1*0408, DRB11001 and DRB1*1402 encoding the RAA sequence of amino acids in 72 to 74 positions in the third hypervariable region of the DR $\beta 1$ chain (known as shared epitope - SE). There have been hundreds of studies, including molecular biology techniques, but still the association with these alleles remains a huge debate because many have demonstrated that each allele does not confer the same risk.

\section{Material, method}

Thirty five patients diagnosed with early rheumatoid arthritis according to new classification criteria ACR/EULAR 2010 in Rheumatology 
department of Central Emergency Hospital, Constanta, Romania (2011-2012) were included in the study and eighty nine healthy volunteer individuals matched by gender, age and ethnic origin were allocated for the control group. Genomic DNA isolation and HLA-DRB1 genotyping were determined in Division of Genetics, Faculty of Medicine, "OVIDIUS" University, Constanta during 2012. Genotyping of HLA-DRB1 as low-resolution allele and HLA-DRB $1 * 04$ subgroups of allele as high resolution were determined by using PCR-SSP kits (InnoTrain Diagnostik GmbH, Germany; ProTrans produkte $\mathrm{GmbH}$, Germany through BioSupply) based on polymerase chain reaction, which enables amplification ofDNA sequences, followed by sequence specific priming in which only the sequence of primer is responsible for the specification of the allele that has to be identified. Results of molecular detection were evaluated in agarose gel electrophoresis under UV light. Due to dimension of population groups, statistical analysis used chi-square test for evaluation of the statistical significance of differences in DRB1 allele frequencies in patients and in controls. Was considered statistically significant a $p$ value of $<0.05$.

\section{Results}

Demographic characteristics of patients with early rheumatoid arthritis diagnosed according to new classification criteria ACR/EULAR 2010 (mean score: 6.48) are summarized in Table no. I, and presented a frequency of HLA-DRB $1 *$ heterozygots of $31.42 \%$ in contrast with the one in controls of $17.97 \%$. Female/male sex ratio was - $4: 1$, with $82.86 \%$ in favor of females. Rheumatoid factor (RF) was found positive in $57.14 \%$ (a mean value of $95.45 \mathrm{UI}$ ) of patients with early rheumatoid arthritis, and anticitrullinated peptide antibodies (ACPs) were positive for $45.71 \%$ (a mean value of $292.75 \mathrm{UI}$ ). Biologic syndrome of inflammation showed a a mean value for erythrocyte sedimentation rate (ESR) of 50.61 +/-
$28.45 \mathrm{~mm} / 1 \mathrm{~h}$ and of $3.58+/-3.85 \mathrm{mg} / \mathrm{L}$ for $\mathrm{C}$ reactive protein (CRP).

Table I - Demographic characteristics of patients with early rheumatoid arthritis

\begin{tabular}{|l|c|}
\hline \multicolumn{1}{|c|}{ Characteristics } & No. $=\mathbf{3 5}$ \\
\hline Age, mean +/- SD (years) & $58.6+/-12.35$ \\
\hline Male & $6(17.14 \%)$ \\
\hline Female & $29(82.86 \%)$ \\
\hline Male / female ratio & $1: 4$ \\
\hline ACR/EULAR2010 score (mean) & 6.48 \\
\hline RF positive & $20(57.14 \%)$ \\
\hline RF mean +/SD $(\mathrm{UI} / \mathrm{mL})$ & $95.45+/-117.88$ \\
\hline ACPs positive & $16(45.71 \%)$ \\
\hline ACPs mean $+/-S D(\mathrm{UI} / \mathrm{mL})$ & $292.75+/-154.31$ \\
\hline ESR mean $+/-S D(\mathrm{~mm} / \mathrm{h})$ & $50.61+/-28.45$ \\
\hline CRP mean $+/-S D(\mathrm{mg} / \mathrm{L})$ & $3.58+/-3.85$ \\
\hline$* 04$ heterozygots & $11(31.42 \%)$ \\
\hline
\end{tabular}

(ACP-anti-citrullinated peptide antibodies; ACR/EULAR 2010-American College of Rheumatology/ European

League against Rheumatoid Arthritis 2010; CRP-C reactive protein; ESR-erythrocyte sedimentation rate; $R F$ rheumatoid factor; SD-standard deviation)

Tables II and III show the distribution of allele frequencies observed in patients with early rheumatoid arthritis and healthy individuals. HLADRB1 allele genotyping showed statistically significant differences given by a higher allele frequency for *04 (15.71\%vs.8.98\%; p-0.0101), *01 $(12.85 \%$ vs $8.42 \%$; $p-0.0296)$ and $* 14(15.71 \%$ vs. $8.42 \%$; -0.008$)$, all of them being potentially carriers of shared epitope (SE) in rheumatoid arthritis group in contrast with controls.

Also, inourstudywasobservedalowerfrequency for $* 03\left(11.42 \%\right.$ vs. $13.48 \%$; p-0.0009), ${ }^{*} 11(11.42 \%$ vs. $20.22 \% ; \quad$ p $<0.0001),{ }^{*} 13(7.14 \% \quad$ vs. $14.60 \%$; $\mathrm{p}<0.0001)$ and $* 15(7.14 \%$ vs. $12.35 \% ; \mathrm{p}-0.0009)$ HLA-DRB1 allele in patients group compared with controls.

Related to overall distribution of allele HLADRB1 potentially containing SE $\left(* 01, * 04,{ }^{*} 10,{ }^{*} 14\right)$, an important frequency was determined in patients with early rheumatoid arthritis (38.57\% vs. $21.91 \%$; p-0.0005). 
Table II - The frequencies of HLA-DRB1 alleles in patients with early rheumatoid arthritis (ERA) and controls

\begin{tabular}{|c|c|c|c|c|c|}
\hline \multirow{2}{*}{$\begin{array}{l}\text { HLA-DRB1 } \\
\text { alleles }\end{array}$} & \multicolumn{2}{|c|}{$\operatorname{ERA}(2 \mathrm{no} .=70)$} & \multicolumn{2}{|c|}{ Control $(2 \mathrm{no.}=178)$} & \multirow{2}{*}{$\begin{array}{l}\text { p value } \\
(<0.05)\end{array}$} \\
\hline & No. & Freq. (\%) & No. & Freq. (\%) & \\
\hline$* 01$ & 9 & $12.85 \%$ & 15 & $8.42 \%$ & 0.0296 \\
\hline$* 03$ & 8 & $11.42 \%$ & 24 & $13.48 \%$ & 0.0009 \\
\hline$* 04$ & 11 & $15.71 \%$ & 16 & $8.98 \%$ & 0.0101 \\
\hline$* 07$ & 5 & $7.14 \%$ & 6 & $3.37 \%$ & 0.0362 \\
\hline$* 08$ & 0 & $0 \%$ & 2 & $1.12 \%$ & - \\
\hline$* 10$ & 2 & $2.85 \%$ & 2 & $1.12 \%$ & 0.1021 \\
\hline$* 11$ & 8 & $11.42 \%$ & 36 & $20.22 \%$ & $<0.0001$ \\
\hline$* 12$ & 1 & $1.42 \%$ & 0 & $0.00 \%$ & - \\
\hline$* 13$ & 5 & $7.14 \%$ & 26 & $14.60 \%$ & $<0.0001$ \\
\hline$* 14$ & 5 & $7.14 \%$ & 6 & $3.37 \%$ & 0.0362 \\
\hline$* 15$ & 5 & $7.14 \%$ & 22 & $12.35 \%$ & 0.0009 \\
\hline$* 16$ & 11 & $15.71 \%$ & 23 & $12.92 \%$ & 0.0087 \\
\hline $\begin{array}{l}\text { Main alleles potentially } \\
\text { containing SE } \\
\left(\operatorname{sum} * 01, * 04, * 10,{ }^{*} 14\right)\end{array}$ & 27 & $38.57 \%$ & 39 & $21.91 \%$ & 0.0005 \\
\hline
\end{tabular}

According to the distribution of HLADRB1*04 subgroups, it was registered a high frequency for $* 0404$ and $* 0408$ allele $(18.18 \%$ vs. $6.25 \% ; \mathrm{p}<0.0001)$, in contrast with $* 0401$ and $* 0402$ which were significantly lower in patients than in controls. $* 0403$ and $* 0405$ subgroup allele were slightly decreased in early rheumatoid arthritis group, but the differences with controls are not statistically significant.

Table III - The frequencies of HLA-DRB1*04 subgroup alleles in patients with early rheumatoid arthritis and controls

\begin{tabular}{|c|c|c|c|c|c|}
\hline \multirow{2}{*}{$\begin{array}{c}\text { DRB1 } \\
\text { subgrou } \\
\text { alleles }\end{array}$} & \multicolumn{2}{|c|}{ ERA (no. $=\mathbf{1 1 )}$} & \multicolumn{2}{|c|}{$\begin{array}{c}\text { Control (no. } \\
=\mathbf{1 6})\end{array}$} & \multirow{2}{*}{ p value } \\
\cline { 2 - 5 } & No. & $\begin{array}{c}\text { Freq. } \\
(\%)\end{array}$ & No. & $\begin{array}{c}\text { Freq. } \\
(\%)\end{array}$ & \\
\hline$* 0401$ & 1 & $9.09 \%$ & 3 & $18.75 \%$ & 0.0120 \\
\hline$* 0402$ & 2 & $18.18 \%$ & 5 & $31.25 \%$ & 0.0070 \\
\hline$* 0403$ & 1 & $9.09 \%$ & 2 & $12.5 \%$ & 0.2317 \\
\hline$* 0404$ & 2 & $18.18 \%$ & 1 & $6.25 \%$ & $<0.0001$ \\
\hline$* 0405$ & 2 & $18.18 \%$ & 3 & $18.75 \%$ & 0.5637 \\
\hline$* 0406$ & 0 & 0 & 1 & $6.25 \%$ & - \\
\hline$* 0407$ & 1 & $9.09 \%$ & 0 & 0 & - \\
\hline$* 0408$ & 2 & $18.18 \%$ & 1 & $6.25 \%$ & $<0.0001$ \\
\hline
\end{tabular}

\section{Discussions}

In various ethnical or racial groups, the overall biogeografical distribution of HLA-DRB1 is very different $[3,4,6]$. An important goal of our study comes from the lack of studies on this issue in our country. Specifically, the HLA-DRB1 alleles are associated with rheumatoid arthritis based on the SE hypothesis and, implicitly, they are associated with the severity of the disease. Many anterior prospective studies enlightened that the highest risk in developing aggressive, erosive disease is present in carriers of *04 alleles, in contrast with the low risk of carriers of *01 allele $[5,6,8] . * 04$ allele was associated with rheumatoid arthritis in many populational studies according to literature $[7,8,10]$, and specifically with DRB1 *0401 and *0404 subgroups. Other associations with rheumatoid arthritis are implying DRB1*01 in French [7], Latin-Americans [9,10], Asians [11,12] and Caucasian's [13,14], DRB1*09 
in Asians [12], Chileans [9], Koreans [15,16] and Caucasoid people in Great Britain [3]. The results of our study are in accordance with previous reports, especially related to Caucasian's, showing that the susceptibility in developing rheumatoid arthritis, in our particular study in early forms, is predominately associated with $* 04, * 01$ and $* 14$ allele.

The limitation of this study resides in the fact that were sub-typed only DRB1*04 allele, having in mind that sub-typing also DRB $1 * 01$ and $* 10$ allele would have offered other subgroups common for shared epitope. Still, the study determined a statistically significant relationship with allele potentially containing shared epitope (as $* 01, * 04, * 10, * 14)$ in patients with early rheumatoid arthritis.

Moreover, in *04 subgroups that contain SE, *0404 and *0408 allele that carry QRRAA amino acids in positions $70-74$ of $\beta$ peptide chain was significantly associated with early rheumatoid arthritis in our study, in net contrast with reports from other populations in geographical area like the Turkish or Hungarians which associated significantly *0401[22,23]. Contrarily, *0402 presented a negative association with the disease, in definite accordance with scientific literature. $* 0403, * 0405$ and $* 10$ were not associated with early rheumatoid arthritis in our group diagnosed according with new classification criteria ACR/EULAR 2010.

It is poorly understood and investigated the protective role of HLA DRB1 allele. Research performed on mice showed the importance of aspartic acid (D) in 70th position related to protection against rheumatoid arthritis [17]. In present study we found a negative association of $* 0402, * 11$ and *13 (which present D amino acid in 70th position of $\beta$ chain) with early rheumatoid arthritis, fact that can be considered previously demonstrated, at least for $* 0402$, as universal protection against arthritis in American Yakima indigenes' [17], or for *13 in Asians [12,15,18], Danish [19], Turkish [13,22], Finnish [20] or Caucasians' [21].

\section{Conclusions}

The analysis offered by our study demonstrates the association ofHLA-DRB1 allele and *04 subgroups containing SE and early rheumatoid arthritis cases diagnosed according to new classification criteria ACR/EULAR 2010.

Results of our study are demonstrating the need of a continuous work of allele tracing and associating with rheumatoid arthritis, especially in cases early diagnosed in order to create sufficient premises for instituting a correct and possibly long term remissive treatment.

\section{References}

1. Silman, A.J., MacGregor, A.J., Thomson, W., Holligan, S., Carthy, D., Farhan A. \& Ollier, W.E. (1993). Twin concordance rates for rheumatoid arthritis: results from a nationwide study. $\mathrm{Br} J$ Rheumatol. 32, 903-907.

2. Gregersen, P.K., Silver, J. \& Winchester, R.J. (1987). The shared epitope hypothesis: an approach to understanding the molecular genetics of susceptibility to rheumatoid arthritis. Arthritis Rheum. 30, 1205-1213

3. Kochi, Y., Suzuki, A., Yamada R., \& Yamamoto, K. (2009). Genetics of rheumatoid arthritis: underlying evidence of ethnic differences. $J$ Autoimmun. 32, 158-162

4. Imboden, J.B. (2009). The immunopathogenesis of rheumatoid arthritis. Annu Rev Pathol. 4, 417434

5. Alvarez, I., Collado, J., Daura, X., Colome, N., Rodriguez-Garcia, M. \& Gallart, T. et al. (2008). The rheumatoid arthritis-associated allele HLADR10 (DRB1*1001) shares part of its repertoire with HLA-DR1 (DRB1*0101) and HLA-DR4 (DRB*0401). Arthritis Rheum. 58, 1630-1639 
6. Gonzalez-Gay, M.A., Garcia-Porrua, C. \& Hajeer, A.H. (2002). Influence of human leukocyte antigen-DRB1 on the susceptibility and severity of rheumatoid arthritis. Semin Arthritis Rheum. $31,355-360$

7. Reviron, D., Foutrier, C., Guist, S., Mercier, P. \& Roudier, J. (2001). DRB1 alleles in polymyalgia rheumatica and rheumatoid arthritis in southern France. Eur J Immunogenet. 28, 83-87

8. Saruhan-Direskeneli, G., SG IR (1998). Shared epitope "Homozygosity" is strongly associated with RA patients in Turkey. Br J Rheumatol. 37, 1126-1128

9. Delgado-Vega, A.M. \& Anaya, J.M. (2007). Meta-analysis of HLADRB1polymorphism in Latin American patients with rheumatoid arthritis. Autoimmun Rev. 6, 402-408

10. del Rincon, I. \& Escalante, A. (1999). HLADRB1 alleles associated with susceptibility or resistance to rheumatoid arthritis, articular deformities, and disability in Mexican Americans. Arthritis Rheum. 42, 1329-1338

11. Takeuchi, F., Nakano, K., Matsuta, K., Nabeta, H., Bannai, M., Tanimoto, K. \& Ito, K. (1996). Positive and negative association of HLADR genotypes with Japanese rheumatoid arthritis. Clin Exp Rheumatol. 14, 17-22

12. Jun, K.R., Choi, S.E., Cha, C.H., Oh, H.B., Heo, Y.S., Ahn, H.Y. \& Lee, K.J. (2007). Meta-analysis of the association between HLA-DRB1allele and rheumatoid arthritis susceptibility in Asian populations. J Korean Med Sci. 22, 973-980

13. Kinikli, G., Ates, A., Turgay, M., Akay, G., Kinikli, S. \& Tokgoz, G. (2003). HLA-DRB1 genes and disease severity in rheumatoid arthritis in Turkey. Scand J Rheumatol. 32, 277-280

14. Milicic, A., Lee, D., Brown, M.A., Darke, C. \& Wordsworth, B.P. (2002). HLA-DR/DQ haplotype in rheumatoid arthritis: novel allelic associations in UK Caucasians. J Rheumatol. 29, 1821-1826

15. Lee, H.S., Lee, K.W., Kim Song, G.G., HA Kim, S.Y. \& Bae, S.C. (2004). Increased susceptibility to rheumatoid arthritis in Koreans heterozygous for HLA-DRB1*0405 and *0901. Arthritis Rheum. 50, 3468-3475

16. Kim, T.G., Choi, H.B., Park, S.H., Kim, H.Y.
\& Han, H. (1999). DQCAR 113 and DQCAR 115 in combination with HLA-DRB1 alleles are significant markers of susceptibility to rheumatoid arthritis in the Korean population. Tissue Antigens. 54, 552-559

17. Mattey, D.L., Dawes, P.T., Gonzalez-Gay, M.A., Garcia-Porrua, C., Thomson, W., Hajeer, A.H. \& Ollier, W.E. (2001). HLA-DRB1 alleles encoding an aspartic acid at position 70 protect against development of rheumatoid arthritis. $J$ Rheumatol. 28, 232-239

18. Xue, Y., Zhang, J., Chen, Y.M., Guan, M., Zheng, S.G. \& Zou, H.J. (2008). The HLA-DRB1 shared epitope is not associated with antibodies against cyclic citrullinated peptide in Chinese patients with rheumatoid arthritis. Scand J Rheumatol. $37,183-187$

19. de Vries, N., Tijssen, H., van Riel, P.L. \& van de Putte, L.B. (2002). Reshaping the shared epitope hypothesis: HLA-associated risk for rheumatoid arthritis is encoded by amino acid substitutions at positions 67-74 of the HLA-DRB1 molecule. Arthritis Rheum. 46, 921-928

20. Tuokko, J., Nejentsev Luukkainen, R., Toivanen, A. \& Ilonen, J. (2001). HLA haplotype analysis in Finnish patients with rheumatoid arthritis. Arthritis Rheum. 44, 315-322

21. Morgan, A.W., Haroon-Rashid, L., Martin, S.G., Gooi, H.C., Worthington, J., Thomson, W., Barret, J.H. \& Emery, P. (2008). The shared epitope hypothesis in rheumatoid arthritis: evaluation of alternative classification criteria in a large UK Caucasian cohort. Arthritis Rheum. $58,1275-1283$

22. Ucar, F., Karkucak, M., Alemdaroglu, E., Capkin, E., Yucel, B., Sonmez, M., Tosun, M. \& Karaca, A. (2012). HLA-DRB1 allele distribution and its relation to rheumatoid arthritis in eastern Black Sea Turkish population. Rheumatol Int. 32, 1003-1007; DOI: 10.1007/s00296-010-1792-8

23. Kapitany, A., Zilahi, E., Szanto, S., Szucs, G., Szabo, Z., Vegvari, A., Rass, P., Sipka, S., Szegedi, G. \& Szekanecz, Z. (2005). Association of rheumatoid arthritis with HLA-DR1 and HLA-DR4 in Hungary. Ann N Y Acad Sci. 1051, 263-70. 